\title{
Avances en tecnologías de propagación y domesticación de plantas de interés económico y ambiental en Argentina
}

\author{
Advances in technologies for propagation and domestication of plants of economic and \\ environmental interest in Argentina
}

\begin{abstract}
E. S. Sharry¹, C. Weber², M. Cellini², V. Lien², P. Boeri³ , L. Roussy², P. Sceglio², D. Ramilo², S. Galarco²～DOI. 10.21931/RB/2021.06.01.16 Resumen: En el Laboratorio de Estudios de la Madera de la Facultad de Ciencias Agrarias y Forestales de La Universidad Nacional de La Plata, Argentina, se implementa el proyecto de desarrollo tecnológico denominado Métodos y tecnologías de propagación y domesticación de plantas para el desarrollo de una bioeconomía local basada en la biodiversidad. El objetivo del mismo es desarrollar, optimizar y adaptar nuevas metodologías y tecnologías de propagación y conservación de recursos genéticos vegetales para la producción de plantas en nuevo escenario de la bioeconomía nacional. La diversidad está en la base de la bioeconomía, y muchas veces el material vegetal para plantar para diferentes fines es escaso. Las especies contempladas en éste proyecto son: Quercus sp.; Polylepis tarapacana; Prosopis alpataco, Eranthemun pulchelum y Heteropteris angustifolia Griseb. En este trabajo se comunican algunos de los avances alcanzados aplicando diferentes enfoques para la producción de plantas de calidad (semillas, cultivo de tejidos in vitro, macropropagación y plantines en contenedores)
\end{abstract}

\section{Palabras clave: Bioeconomía, Quercus, Prosopis alpataco, Polylepis, Eranthemun pulchelum y Heteropteris angustifolia.}

Abstract: The Timber Research Laboratory of the Faculty of Agricultural and Forestry Sciences of the National University of La Plata (LIMAD), Argentina, implements the technological development project called Methods and technologies of plant propagation and domestication for the development of a local bioeconomy based on biodiversity. Its objective is to develop, optimize and adapt new methodologies and technologies for the propagation and conservation of plant genetic resources for the production of plants in a new scenario of national bioeconomy. Diversity is at the base of bioeconomy, and often planting plant material for different purposes is scarce. The species covered by this project are: Quercus sp. (exotic forest); Polylepis tarapacana (native forest); Prosopis alpataco. (multipurpose native forestry), Eranthemun pulchelum and Heteropteris angustifolia Griseb (ornamental species of great potential and use in green roofs). This work communicates some of the progress made by applying different approaches to the production of quality plants (seeds, in vitro tissue culture, macro propagation and seed container planting)

Key words: Bioeconomy, Quercus, Prosopis alpataco, Polylepis, Eranthemun pulchelum and Heteropteris angustifolia.

\section{Introducción}

El auge actual de uso de especies vegetales nativas y exóticas para usos múltiples y la falta de estudios de sus sistemas de multiplicación, obliga no solo a mejorar los métodos de conservación sino también a mejorar los métodos de propagación sexual y asexual, la calidad del material de siembra o plantación a campo y los métodos de cultivo. La propagación de plantas ha sido ampliamente reconocida como una práctica fundamental en el campo de las ciencias agrícolas ya que de la calidad de la semilla botánica o material vegetativo que se utilice, va a depender el resto del proceso productivo. De algunas especies de interés, falta material de propagación genéticamente mejorado y faltan conocimientos tecnológicos para llevarlo al cultivo y manejarlo a campo en forma eficiente. Es por ello que se deben abordar las diferentes soluciones para ir sentando las bases del conocimiento y desarrollo tecnológico para finalizar con la entrega a la sociedad de productos concretos de material de propagación mejorado y tecnología para su cultivo eficiente. Este tipo de investigación permitiría generar material de propagación genéticamente adecuado y desarrollar la innovación necesaria para introducir al cultivo especies de uso actual o potencial estableciendo las bases tecnológicas para un programa de mejoramiento genético a largo plazo², la domesticación y la disponibilidad de material para realizar paisajismo, forestación y restauración eco sistémica. En el Laboratorio de Estudios de la Madera (LIMAD) de la Facultad de Ciencias Agrarias y Forestales de la Universidad Nacional de La Plata, Argentina, se implementa el proyecto de desarrollo tecnológico denominado Métodos y tecnologías de propagación y domesticación de plantas para el desarrollo de una bioeconomía local basada en la biodiversidad. El objetivo del mismo es desarrollar, optimizar y adaptar nuevas metodologías y tecnologías de propagación y conservación de recursos genéticos vegetales para la producción de plantas en nuevo escenario de la bioeconomía nacional. La diversidad está en la base de la bioeconomía, y muchas veces el material vegetal para plantar para diferentes fines es escaso. Las especies contempladas en éste proyecto son: Quercus sp. (forestal exótica); Polylepis tarapacana; Prosopis alpataco, Eranthemun pulchelum y Heteropteris angustifolia Griseb. La selección de las especies se realizó en primer lugar en base a su uso actual o potencial, definida como las potencialidades de la especie para una buena adaptación a crecer y desarrollarse en condiciones de cultivo, razonable velocidad de crecimiento, adecuada calidad para asegurar un producto diferenciado y

\footnotetext{
${ }^{1}$ Facultad de Ciencias Agrarias y Forestales, Universidad Nacional de La Plata, Buenos Aires, Argentina. Unidad Integrada para la Innovación del Sistema Agroalimentario de la Patagonia Norte, UIISA; Centro de Investigación y Transferencia de Río Negro, CIT-RN-CONICET, Universidad Nacional de Río Negro, Río Negro, Argentina.

${ }^{2}$ Facultad de Ciencias Agrarias y Forestales, Universidad Nacional de La Plata, Buenos Aires, Argentina.

${ }^{3}$ Unidad Integrada para la Innovación del Sistema Agroalimentario de la Patagonia Norte, UIISA; Centro de Investigación y Transferencia de Río Negro, CIT-RN-CONICET, Universidad Nacional de Río Negro, Río Negro, Argentina.
} 
un reconocimiento actual de la misma sobre posibilidades del mercado que allane el camino futuro de su comercialización. Adicionalmente, se tuvo en cuenta la erosión genética sufrida por las diferentes especies (estrechamente relacionada con la demanda actual o pasada) y la necesidad urgente de definir e instalar unidades de conservación para mantener la población base del programa de domesticación y mejora a largo plazo. La producción masiva de plantas mediante la combinación de sistemas de propagación tradicionales, macro y micropropagación (biotecnologías), los ensayos de aclimatación de las plantas y el establecimiento a campo, permitiría producir fácilmente plantas en periodos de tiempo corto. En este trabajo se comunican algunos de los avances alcanzados.

\section{Las especies}

Polylepis tarapacana es un árbol de hábito simpódico, presentando un tronco corto y pudiendo alcanzar tres metros de altura ${ }^{3}$. Es tolerante a las heladas, minimizando el daño tisular por su capacidad de sobreenfriamiento y reducir la pérdida de agua por control estomático ${ }^{4,5}$. Las hojas son perennes ${ }^{6}$, y la floración se produce en un amplio período de tiempo, mientras que la maduración de frutos ocurre entre los meses de abril y junio ${ }^{7}$. Los bosques de P. tarapacana se encuentran en la provincia fitogeográfica Altoandina de la Argentina, presentando un clima frío y seco con precipitaciones en forma de nieve o de granizo en cualquier época del año $0^{8,9}$. El objetivo de esta parte de la investigación fue determinar la producción, biometría y viabilidad de flores y semillas en árboles y arbustos de P. tarapacana, como primer paso para caracterizar su biología reproductiva en vistas a su conservación y propagación.

Prosopis alpataco es una especie arbórea de Sudamérica, de la familia de las leguminosas, que habita el centro oeste de Argentina, la ecorregión de Gran Chaco y zonas semiáridas del Noroeste Argentino, Cuyo y la Patagonia argentina. Es una especie clave del Monte, una de las ecorregiones sudamericanas más amenazadas. En esta región, varios factores limitan la producción de las plantas nativas, entre ellas el desconocimiento de su sistema de reproducción, el ajuste de técnicas de propagación sexual y asexual y el comportamiento a campo de estas plantas propagadas. P. alpataco se propaga naturalmente por semillas, y se ha logrado ajustar la embriogénesis somática ${ }^{10}$; sin embargo, no hay reportes previos de la propagación in vitro por organogénesis. El objetivo de esta parte de la investigación fue micro propagar vía organogénesis, explantes de alpataco con el objeto de multiplicar masivamente esta planta.

Eranthemum pulchellum A. es una especie de la familia Acantaceae, de origen asiático e introducida en Argentina con fines paisajísticos. Es un arbusto perenne y de muy amplia ramificación. Posee una extraordinaria floración color azul francia en pleno invierno y sus hojas color verde brillante le otorgan un gran atractivo visual. Es una planta que puede alcanzar 1,6-1-8 $\mathrm{m}$ de altura y un diámetro de mata de 1,2-1,5 m. (su rápido crecimiento le permite alcanzar el tamaño definitivo en una sola temporada). Se adapta a situaciones de bajas temperaturas, aunque no soporta heladas ni temperaturas cercanas a cero grados o bajo cero. Bajo estas situaciones no muere la planta, pero sí tiene una defoliación importante; luego rebrota en primavera bajo temperaturas cálidas. En estos casos se pierde su floración de fines de invierno. Las excepcionales flores de color azul profundo son pequeñas, están compuestas de cinco pétalos y dos largos filamentos, que se producen en espigas terminales y erectas y que se alzan por encima del conjunto de la mata.
Heteropteris angustifolia es una especie de la familia Malpighiaceae, nativa endémica de Argentina, Brasil, Paraguay y Uruguay. Es un arbusto caduco, que puede alcanzar los 2,5 $\mathrm{m}$ de altura. Posee una floración amarilla que convive con su fruto sámara color rojo en primavera, verano y parte del otoño. Produce un diámetro de mata de $1-1,5 \mathrm{~m}$. y se adapta fácilmente a situaciones de sequedad temporal. Es una planta heliófila, aunque puede sobrevivir bajo dosel arbóreo. Soporta heladas y bajas temperaturas sin inconvenientes. Posee flores amarillas en una inflorescencia terminal, en racimos terminales o axilares y fruto sámaras rojizas de 2-2,5 cm de largo. Eranthemum pulchellum A y Heteropteris angustifolia tienen uso ornamental. El objetivo de esta parte de la investigación fue avanzar en la etapa 1 de conformación de las plantas madre en invernadero para su posterior propagación. De manera simultánea, se probaron plantaciones in situ de plantas obtenidas a partir de esquejes.

Quercus robur L (roble europeo) es una especie originaria de Europa occidental, se distribuye desde el Océano Atlántico al este hasta los montes Urales y el Mar Caspio al Oeste, y desde Escocia y el sur de Escandinavia hasta España, norte de África y Turquía ${ }^{11,12}$ con una distribución altamente influenciada por la actividad humana ${ }^{13}$ que se adapta a distintas zonas de nuestro país, entre ellas la región de la pampa ondulada. Esta especie reviste interés forestal para su uso como madera entre otros. El objetivo de esta parte de la investigación fue contribuir al conocimiento dela supervivencia y crecimiento inicial de forestaciones con roble europeo en macizos en la zona de La Plata, Argentina. Específicamente se propuso estudiar la supervivencia y el crecimiento inicial aéreo de las plantas en un sistema de macizo.

\section{Materiales y métodos}

\section{Polylepis tarapacana}

Se analizaron 17 de un total de 96 árboles (individuos con una altura mayor a 1,3 m) y arbustos (individuos con una altura menor a 1,3 m) de $P$. tarapacana. Las muestras fueron colectadas en las localidades de Casa Colorada, Liviara, Mina Pirquitas, Susques y Coyahuaima en la provincia de Jujuy, con una altitud entre 4375 y 4620 m s. n. m. A estos 17 individuos se les midió la altura $(\mathrm{H}-\mathrm{cm})$ y el diámetro en la base (DAB $\mathrm{cm})$ con cinta diamétrica. Se utilizó el método de relación del diámetro ${ }^{14}$ para la estimación de la producción de flores y semillas, contando el número de flores y semillas en dos ramas de un individuo y extrapolando al resto de las ramas del árbol. En laboratorio se identificaron como flores aquellas que aún conservaban los estambres y fruto cuando no se observaron, observándose claramente un mayor desarrollo del fruto (Figura 1). La producción de semillas se calculó para árboles y arbustos ya que se observaron diferencias en la producción de semillas debido al porte forestal en Polylepis tomentella Wedd., Rosaceae (especie de características similares y que habita en el rango altitudinal inmediato inferior a $P$. tarapaca$n a)^{15}$, encontrando una relación positiva entre el tamaño de las ramas de los árboles y la producción de flores y frutos. Se aplicó un ANOVA de una vía entre la producción de flores y frutos tomando como factores a los árboles y arbustos. A su vez se realizó un análisis de regresión lineal en arboles (Ar) y arbustos (a), relacionando el diámetro en la base (DAB) y la altura $(\mathrm{H}-\mathrm{cm})$ con la producción de flores y frutos. 

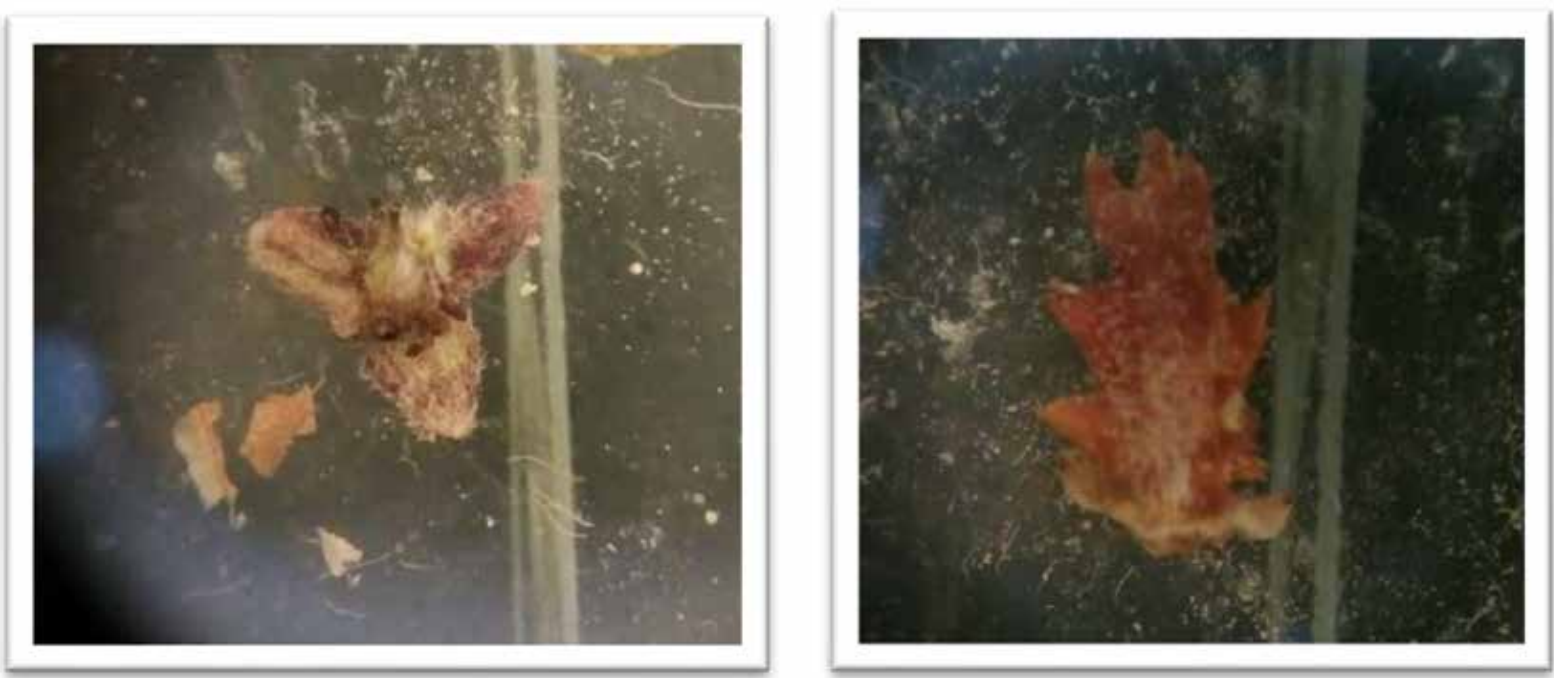

Figura 1. Izquierda: flor de Polylepis tarapacana con estambres. Derecha: fruto Polylepis tarapacana.

\section{Prosopis alpataco}

Se utilizaron segmentos nodales intercalares y apicales como explantes. Los mismos fueron cultivados en envases de vidrio conteniendo el medio de cultivo Murashige-Skoog (MS) ${ }^{16}$ completo sin reguladores de crecimiento (control) o suplementado con diferentes concentraciones de ácido naftalenacético (ANA: 1; 1,5 y $3 \mathrm{mg} / \mathrm{l}$ ). Los frascos fueron mantenidos en cuarto de cultivo, a $25 \pm 2 \stackrel{\circ}{\circ}$ y con ciclo de luz / oscuridad de 16 / 8 horas de luz. Se cultivaron 15 secciones nodales por tratamiento y se realizaron tres repeticiones. A los 30 días de cultivo in vitro se evaluó el porcentaje de enraizamiento, longitud de raíces, formación y número de callos y número de brotes. La formación de nuevos brotes fue evaluada con la cuantificación del número de explantes que produjeron brote y el número de brotes presentes por explante. Mediante un seguimiento histológico, se determinó el lugar de inicio de formación de brotes y las características anatómicas de los folíolos formados in vitro.

\section{Eranthemum pulchellum $A$}

La formación de plantas madre se realizó sobre cajones de $0,5 \mathrm{~m}$ por $0,6 \mathrm{~m}$ de lado y 0,3 $\mathrm{m}$ de profundidad, con sustrato formado con $15 \%$ de perlita, $15 \%$ de arena y $70 \%$ de compost orgánico. La multiplicación fue mediante estacas de 15 cm de largo, sin hojas o con brotes axilares, que fueron colocadas de manera vertical manteniendo la polaridad respectiva y enterradas $7 \mathrm{~cm}$ en el sustrato. La plantación se realizó en la primavera del año 2019 una vez culminada la floración de invierno. Se realizó un riego regular para mantener el sustrato húmedo. Al cabo de un mes de realizada la plantación, las estacas comenzaron un crecimiento pleno, llegando a conformar la mata para florecer a fines del invierno del año 2019. Se obtuvieron 15 plantas madre, de las cuales se obtiene el material vegetal de estacas de calidad, homogeneidad y cantidad para la realización de los ensayos (Figura 2). De manera paralela, se realizaron plantaciones in situ de plantines de Eranthemun pulchellum A. (Figuras 3 y 4) en situaciones de techos verdes intensivos en pulmones de edificios que tienen la característica de muy baja disponibilidad lumínica.

\section{Heteropteris angustifolia Griseb}

Durante el año 2019 se realizó la cosecha de semillas en plantas previamente identificadas y seleccionadas por caracteres fenotípicos de forma de mata, intensidad de floración y fructificación y crecimiento general. La planta proveedora de

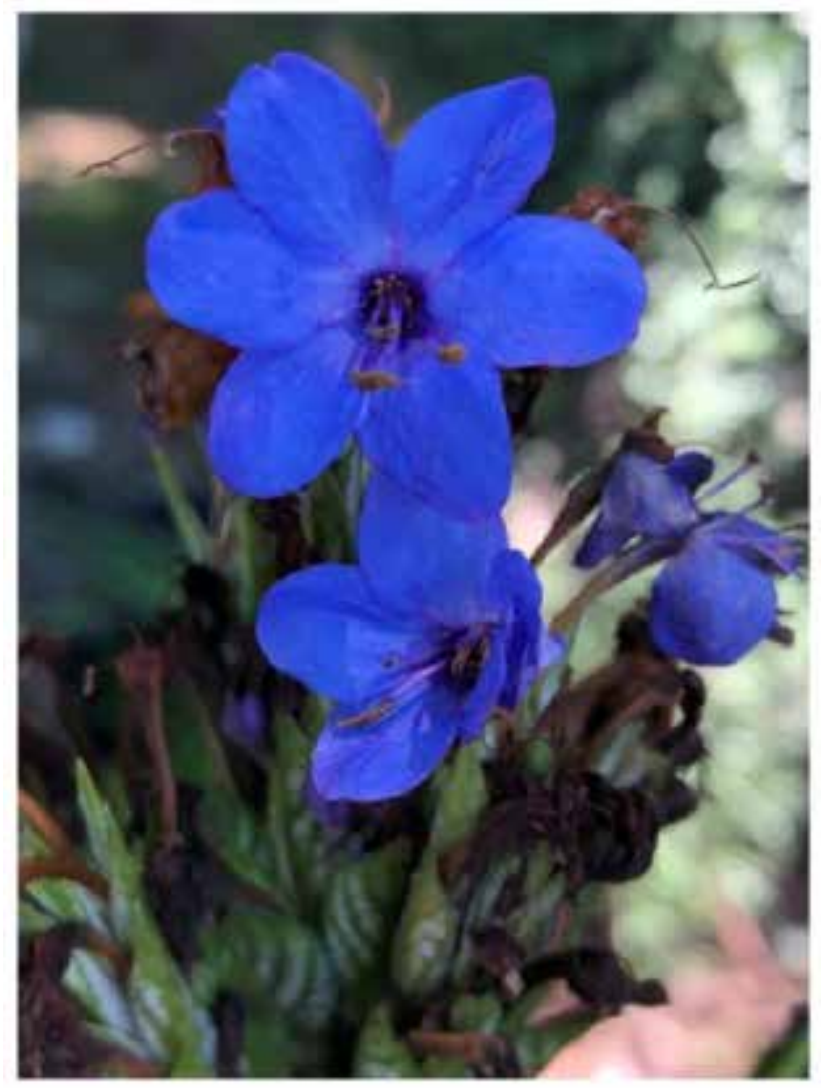

Figura 2. Detalle de flor de planta madre de Eranthemun pulchellum. Invernadero de la Facultad de Ciencias Agrarias y Forestales. Universidad Nacional de La Plata. Octubre 2020.

semillas se encuentra ubicada en el Jardín de la Memoria de la Facultad de Ciencias Agrarias y Forestales, La Plata, Argentina. Se utilizaron las semillas sin tratamiento previo y fueron sembradas en almácigos en los meses de agosto y septiembre. Al cabo de dos meses se trasplantaron a su lugar definitivo en tierra mejorada para la provisión de semillas de calidad. La plantación de plantas madre se realizó sobre tierra mejorada en un $15 \%$ con perlita y un $15 \%$ con arena, buen drenaje y riego y desmalezado durante el primer año. La plantación se realizó en el verano del año 2019. 

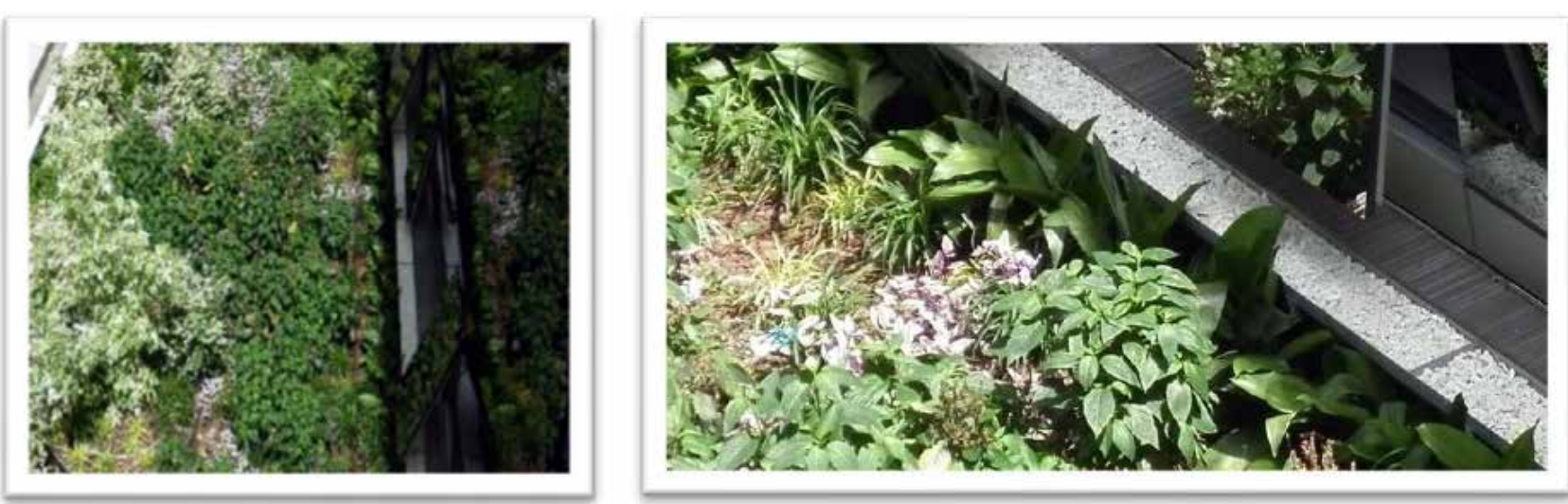

Figura 3 y 4. Plantación in situ en techo verde en patio interno Ciudad Autónoma de Buenos Aires. Año 2018.

\section{Quercus robur $L$.}

Ubicación del ensayo: Estación Experimental Julio Hirschhörn. FCAyF - UNLP. Los Hornos, Pdo. de La Plata.

Descripción de sitio: sitio de loma con antecedentes de cultivo agrícola. Unidad Cartográfica Etch (Etcheverry). 50\% Etcheverry (Paleudol típico), 50\% Ignacio Correa (Paleudol ácuico). El sitio de emplazamiento corresponde a la serie Etcheverry que es el de mayor calidad de la unidad cartográfica.

Tipo de ensayo: Parcela demostrativa.

Diseño: monobloque. Espaciamiento $4 \mathrm{~m} \times 2,5 \mathrm{~m}$. Superficie: 0,5 ha.

Preparación del terreno: laboreo en fajas, que incluyó 1 pasada de arado de reja y vertedera, 1 pasada de disco, 1 pasada de camellonadora, 1 pasada de rotovador y 1 pasada de subsolador en el centro del camellón. Todas las labores realizadas en julio 2019.

Plantación: agosto 2019, utilizando plantas a raíz desnuda $(0+1)$ obtenidas a partir de semilla cosechada de árboles selectos del Parque Provincial Pereyra Iraola (Berazategui, BA).

Al momento de recepción de las plantas del vivero, se observó que una fracción de estas conservaba las hojas secas adheridas al tallo, mientras que las restantes habían perdido totalmente las hojas. La distribución espacial de estas 2 clases de plantas fue al azar en la parcela. Todas las plantas tenían una altura de entre 0,6 y 0,8m y un buen sistema de raíces en cabellera.

Evaluación: medición de Altura total (en cm) con reqla a todas las plantas. Estimación de porcentaje de sobrevivencia (sobrevivencia \%) del total de las plantas del ensayo. Registro de plantas afectadas por hormigas y liebres. Se realizaron 3 mediciones durante la primera temporada de crecimiento, en noviembre 2019 y febrero y junio 2020.

\section{Resultados}

\section{Polylepis tarapacana}

Se observaron diferencias significativas en la producción de flores ( $p=0,0118 \mathrm{~F}: 8,21$ ) y frutos ( $p=0,0052 \mathrm{~F}$ : 10,65) para árboles ( $\mathrm{Ar}$ ) y arbustos (a). Las medias observadas fueron de 83,6 flores en arbustos y 630,8 en árboles; la producción de frutos fue de 189,0 en arbustos y 874.8 en árboles. No encontramos diferencias significativas en la relación entre la producción de flores y la suma de flores y frutos $(p=0,4004 \mathrm{~F}=0,75)$ con medias de 0,37 para arbustos y 0,49 para árboles. Los resultados de la regresión lineal entre producción de flores y el tamaño de la base de los individuos (DAB) muestran una tendencia significativa (R2:62,59) positiva (Producción Flores $=-240,321+50,2284 * D A B)$, al igual que entre producción de frutos y el $D A B\left(R^{2}: 43.3685\right.$; Producción de Frutos $=-57,5761$ + 48,3744* DAB) (Figura 5). Lo mismo se observó entre la altura $(H)$ y la producción de flores $\left(R^{2}\right.$ : 76.6305; Producción

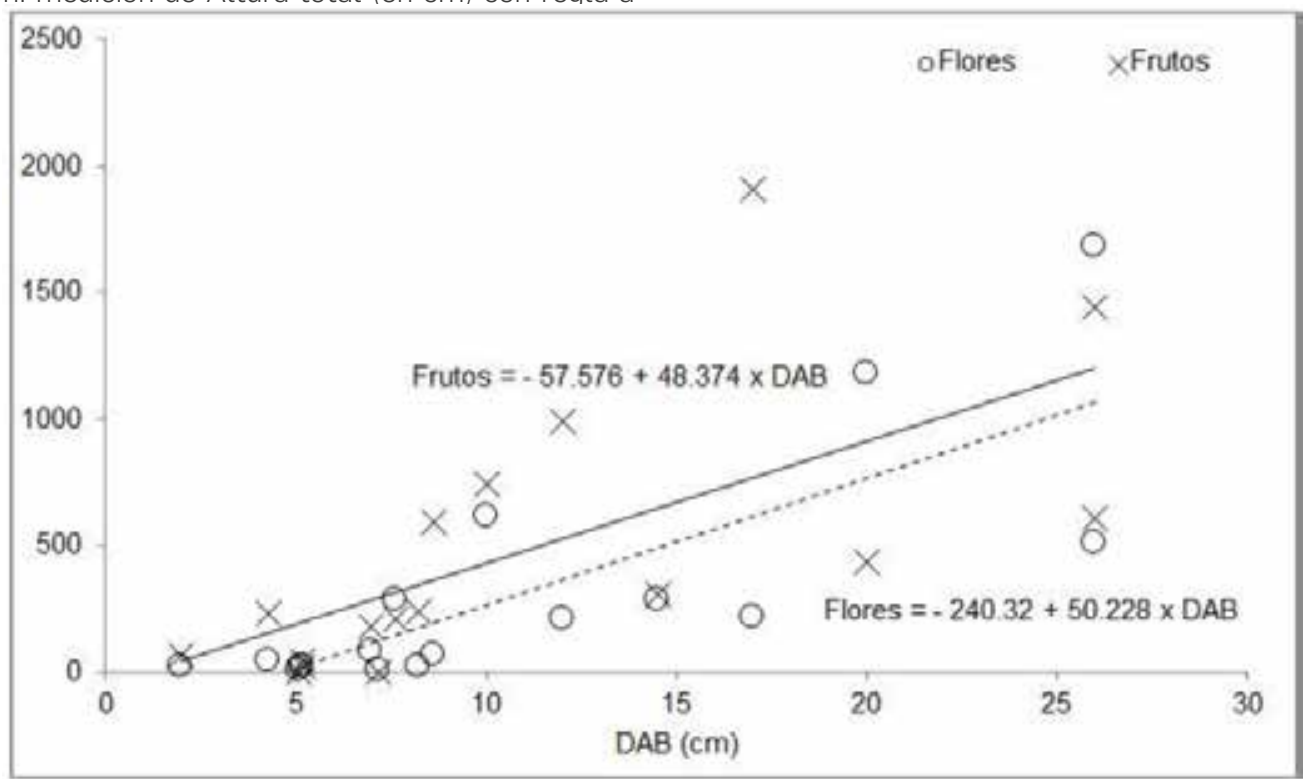

Figura 5. Regresión lineal entre producción de flores y frutos y el diámetro en la base (DAB) en árboles y arbustos de Polylepis tarapacana. 


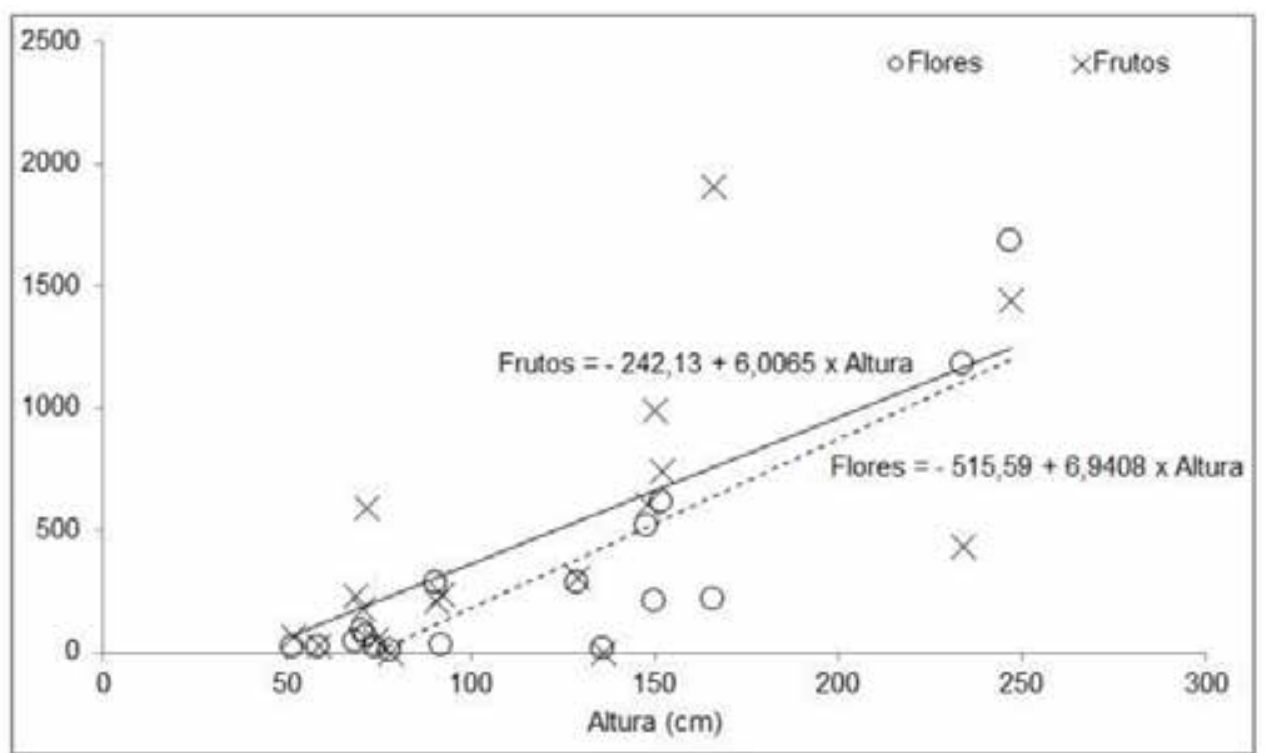

Figura 6. Regresión lineal entre producción de flores y frutos, y la altura ( $\mathrm{H} \mathrm{cm})$ en árboles y arbustos de Polylepis tarapacana.

Flores $\left.=-515,589+6,9408{ }^{*} H\right)$ y frutos $\left(R^{2}: 42.8716\right.$; Producción de Frutos $=-242,128+6,00652 * H)$ (Figura 6).

Estos resultados exploratorios son un indicador de la producción de flores y frutos de la especie. De esta manera podemos inferir la cantidad de semillas a producir en cada estación de reproducción, para estimar la capacidad de regeneración de estos bosques. En una segunda etapa del proyecto, se completará el conteo de flores y frutos y al material colectado se le realizará el análisis de viabilidad, peso y tamaño de semillas para correlacionar estos resultados con los diferentes sitios muestreados. Es necesario aumentar el número de muestras y de observaciones para diseñar nuevos modelos con mejor ajuste estadístico para poder realizar las estimaciones.

\section{Prosopis alpataco}

La Tabla 1 muestra la respuesta morfogénica de los explantes cultivados en medios MS con diferentes concentraciones de ANA ( 0 - 1 - 1,5 - $3 \mathrm{mg} / \mathrm{l}$ ), después de 30 días de cultivo in vitro. El análisis estadístico reveló que no existen diferencias significativas $(p \leq 0,05)$ entre los distintos tratamientos realizados.

Como se desprende la Tabla 1, el número de secciones nodales enraizadas fue superior en la mayor concentración evaluada de ANA (3 mg/l). Sin embargo, de la comparación de las longitudes de las raíces obtenidas en cada caso, surgió que las correspondientes a este tratamiento (t3) fueron las que raíces que menor longitud presentaron. El número de secciones nodales que formaron callos fue en aumento, a medida que la concentración de ANA fue mayor. Lo opuesto ocurrió con los brotes obtenidos, donde el mayor número de explantes que produjeron brotes se observó en el tratamiento sin reguladores de crecimiento (control) y el menor $(18,75)$ en ANA 3 $\mathrm{mg} / \mathrm{l}$. El tratamiento control produjo un promedio de 6 brotes / explante sin embargo éstos permanecieron sin elongar en el mismo medio de cultivo (Figura 7).

Se observaron diferencias cualitativas en el tipo de respuesta organogénica, según el explante inicial utilizado. Cuando el material vegetal consistió en secciones nodales apicales, se formaron callos intercalares con brotes, mientras que el cultivo de secciones intercalares favoreció el proceso de enraizamiento a partir de un callo formado en la zona de corte de los explantes. Los callos obtenidos a partir de secciones nodales presentaron capacidad morfogénica (obtención de brotes y/o raíces) y, a pesar de tratarse de una especie leñosa, no se registraron problemas de oxidación. En la Figura 8 se muestran secciones nodales enraizadas obtenidas mediante organogénesis indirecta e indirecta.

\section{Eranthemum pulchellum A y Heteropteris angustifolia}

Los resultados exploratorios para establecer plantas madre para propagación, y evaluar su comportamiento muestran que Eranthemum pulchellum tiene una excelente adaptabilidad a situaciones de sombra y media sombra, logrando una expresión paisajística plena en cuanto al desarrollo de follaje y la floración a fines de invierno. En este momento, se encuentra en evaluación la medición de la radiación fotosintéticamente activa y variables ambientales en cada una de las situaciones a los fines de poder evaluar el límite de crecimiento y modelizar las situaciones en las que se puede utilizar el material vegetal. Respecto a Heteropteris angustifolia se logró su crecimiento y la producción de las primeras semillas durante el año 20192020 (Figuras 9 y 10).

\section{Quercus robur}

La sobrevivencia general de las plantas dispuesta en el ensayo, transcurridos 10 meses, es baja (58\%), aun cuando

\begin{tabular}{cccccc}
$\begin{array}{c}\text { ANA } \\
(\mathrm{mg} /)\end{array}$ & $\begin{array}{c}\text { Enraizamiento } \\
(\%)\end{array}$ & $\begin{array}{c}\text { Raices/explante } \\
\left(\mathrm{n}^{\circ}\right)\end{array}$ & $\begin{array}{c}\text { Long de } \\
\text { raices(cm) }\end{array}$ & $\begin{array}{c}\text { Explantes } \\
\text { con brotes } \\
(\%)\end{array}$ & $\begin{array}{c}\text { Explantes } \\
\text { con } \\
\text { callos }(\%)\end{array}$ \\
\hline$t 0: 0$ & 4,60 & 1,00 & 2,80 & 83,33 & 10 \\
$t 1: 1$ & 16,67 & 1,00 & 1,80 & 58,33 & 16,66 \\
$t 21,5$ & 16,67 & 1,00 & 1,50 & 33,33 & 38,83 \\
$t 3.3$ & 37,04 & 1,67 & 1,07 & 18,75 & 47,91 \\
\hline
\end{tabular}

Tabla 1. Efecto del ácido naftalenacético (ANA) sobre la organogénesis directa e indirecta de secciones nodales de P. alpataco cultivadas en condiciones in vitro. 


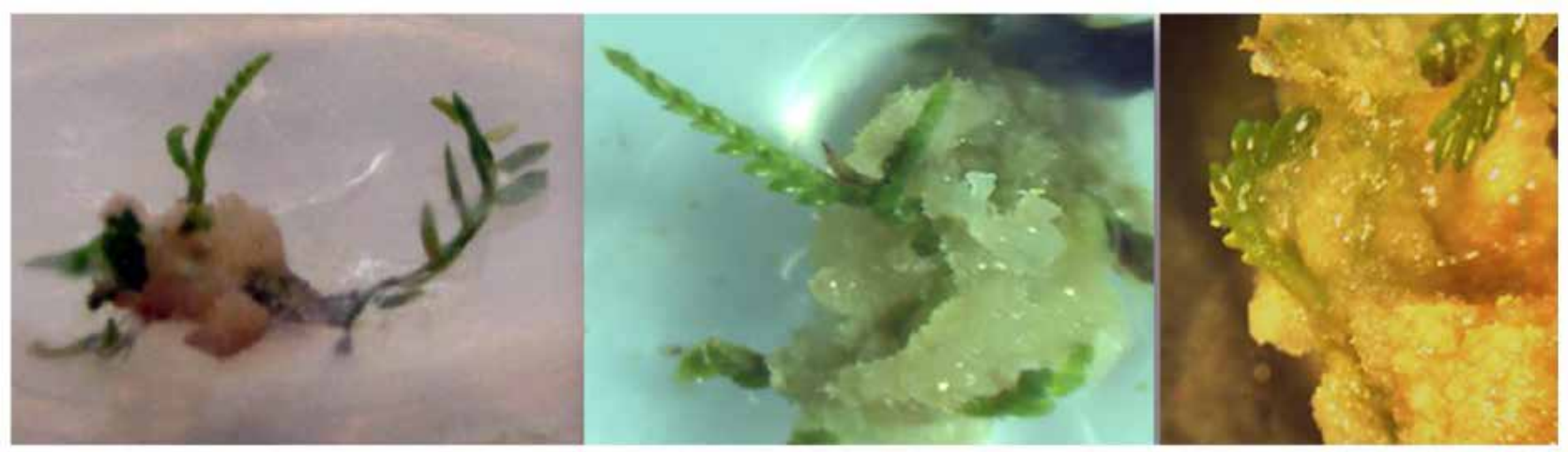

Figura 7. Múltiples brotes obtenidos por organogénesis indirecta de secciones nodales de P. alpataco cultivadas en MS libre de reguladores de crecimiento.

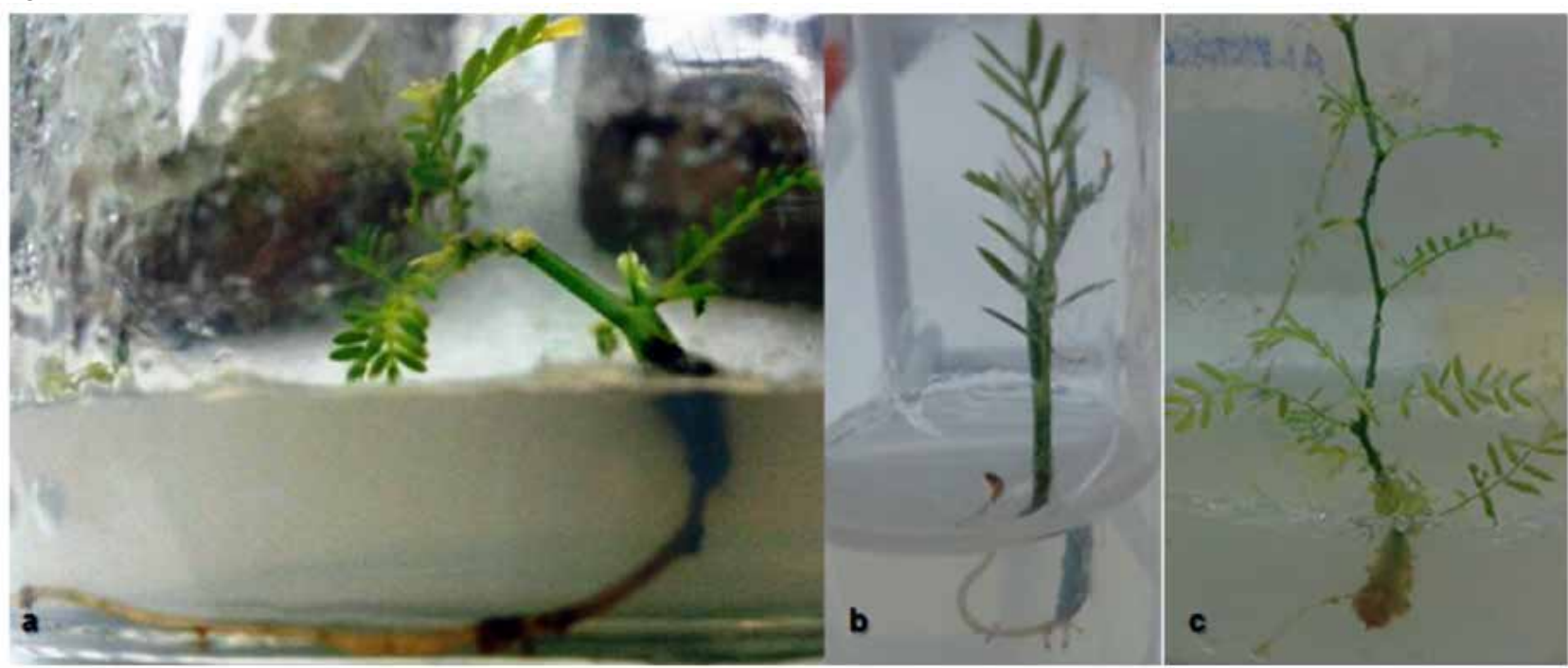

Figura 8. a y b) enraizamiento de secciones nodales vía organogénesis directa de P. alpataco; c) enraizamiento de secciones nodales vía organogénesis indirecta.
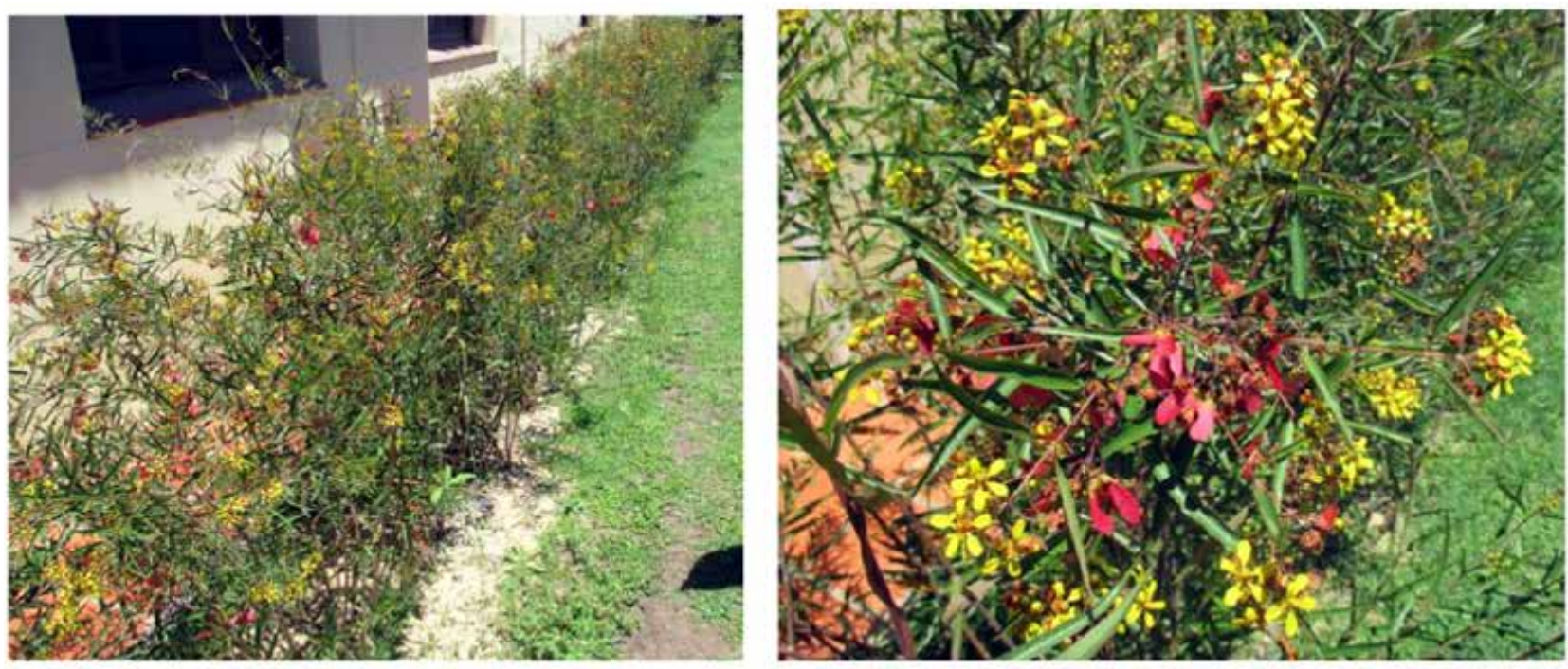

Figura 9 y 10. Plantación de plantas madre para provisión de semillas. Provincia de Buenos Aires. Año 2019.

\begin{tabular}{|l|c|c|c|}
\cline { 2 - 4 } & \multicolumn{3}{c|}{ Fecha medición } \\
\hline Sobrevivencia (\%) & $89 \%$ & feb-20 & jun-20 \\
\hline Muertos & 56 & $68 \%$ & $58 \%$ \\
\hline Vivos & 444 & 160 & 210 \\
\hline Altura media (cm) & no medida & $\mathbf{7 7 , 7}$ & 290 \\
\hline
\end{tabular}

Tabla 2. Resultados preliminares luego de una temporada de crecimiento de plantas de Quercus robur, en la Estación Experimental Julio Hirschhörn. FCAyF UNLP. Los Hornos, Pdo. de La Plata. 
se realizaron 3 riegos durante el verano. Se observa un fuerte descenso de la sobrevivencia durante los meses de verano, pasando de $89 \%$ en noviembre 2019 a 68\% en febrero 2020 (Tabla 2).

El análisis de los registros climáticos obtenidos del Boletín Agrometeorológico Mensual de la Estación Experimental Julio Hirschhörn señalan un período seco que se extendió durante todo el verano, con un almacenaje de agua en el perfil que no supero el 50\% de capacidad de campo $(300 \mathrm{~mm}$ hasta $1 \mathrm{~m}$ de profundidad en el suelo (ocal), determinando una situación de almacenaje de sequía (Tabla 3).

Esta situación climática tuvo su correlato en la condición del suelo en las fajas laboreadas donde puntualmente se colocaron las plantas, al producirse importantes grietas y rajaduras asociadas a la contracción de las arcillas ante la desecación del perfil del suelo laboreado. Este fenómeno se observó en muchas de las plantas muertas, cuyos sistemas de raíces fueron afectados por los procesos de contracción y expansión del suelo producto de la fuerte desecación. Esto nos lleva a pensar que, dentro de la técnica de plantación manual con pala de punta, el aporque y apisonado constituye una tarea de singular importancia que debe realizarse muy cuidadosamente. Durante el período entre mediciones de altura, esta variable registró un incremento de apenas 2 centímetros en promedio. Este valor, aparentemente bajo, ha de interpretarse teniendo en consideración el crecimiento lento de esta especie, las condiciones de fuerte sequía antes descripta, y que se trata de plantas en proceso de instalación. En relación a la presencia o no de hojas secas unidas en las plantas al momento de plantación en invierno 2019, se realizó un seguimiento de la brotación de los 2 grupos, con el propósito de detectar posibles diferencias en esta variable. Los resultados indican que las plantas con hojas presentaron mayor mortalidad post plantación que aquellas sin hojas (Figura 11).

Los resultados, aunque preliminares, podrían aplicarse para seleccionar los materiales de propagación en el vivero, evitando en la medida de lo posible emplear plantas que mantengan adheridas las hojas en invierno. No obstante, es necesario continuar con estudios en este tema. Durante el invierno 2020 se realizó una reposición parcial de las plantas muertas, a fin de completar la parcela. Se prevé continuar con la medición anual del ensayo puesto que para la región no existen antecedentes documentados de cultivo en plantaciones forestales con objetivo maderable de Quercus robur $\mathrm{L}$.

\section{Conclusiones}

Se presentaron resultados preliminares sobre la propagación de algunas especies de interés para Argentina que tienen diversos usos. Se ha logrado avanzar en el conocimiento de la producción de semillas de Polylepis tarapacana, leñosa de importancia en bosques de altura. En Prosopis alpataco se indujo organogénesis indirecta in vitro. Se avanzó en la macro propagación de dos especies ornamentales interesantes para techos verdes y paisajismo. Si bien son resultados exploratorios, estos indican que el propósito integrador de este Proyecto puede alcanzarse. Esperamos generar conocimiento para la caracterización, conservación in situ y ex situ y propagación de bajo costo de germoplasma vegetal con el fin de mantener la

\begin{tabular}{|c|c|c|c|c|c|c|}
\hline Mes & $\begin{array}{l}\text { Pptación } \\
\text { acum (mm) }\end{array}$ & $\begin{array}{l}\text { Temp prom } \\
\max \left({ }^{\circ} \mathrm{C}\right)\end{array}$ & $\begin{array}{l}\text { Temp suelo } \\
\text { prom max } \\
\left({ }^{\circ} \mathrm{C}\right)\end{array}$ & $\mathrm{ETP}(\mathrm{mm})$ & $\begin{array}{l}\text { Situación } \\
\text { almacenaje. }\end{array}$ & \multirow{8}{*}{$\begin{array}{l}\text { Tabla 3. Registros agroclimáticos para el período } \\
\text { post plantación en la Estación Experimental Julio } \\
\text { Hirschhörn. FCAyF - UNLP. Los Hornos, Pdo. de La } \\
\text { Plata. }\end{array}$} \\
\hline oct-19 & 214,4 & 20,5 & 15,1 & 102,4 & NORMAL & \\
\hline nov-19 & 34,8 & 26,6 & 19,6 & 145,8 & ESTRÉS & \\
\hline dic-19 & 82,2 & 28,4 & 20,3 & 170,2 & SEQUIA & \\
\hline ene-20 & 61,8 & 29,1 & 16,6 & 175,7 & SEQUIA & \\
\hline feb-20 & 77,6 & 28,6 & 22,8 & 150 & SEQUIAA & \\
\hline mar-20 & 104 & 27.7 & 21,7 & 110,4 & SEQUÍA & \\
\hline$a b r-20$ & 114.8 & 21.4 & 17,4 & 76,7 & SEQUIA & \\
\hline
\end{tabular}

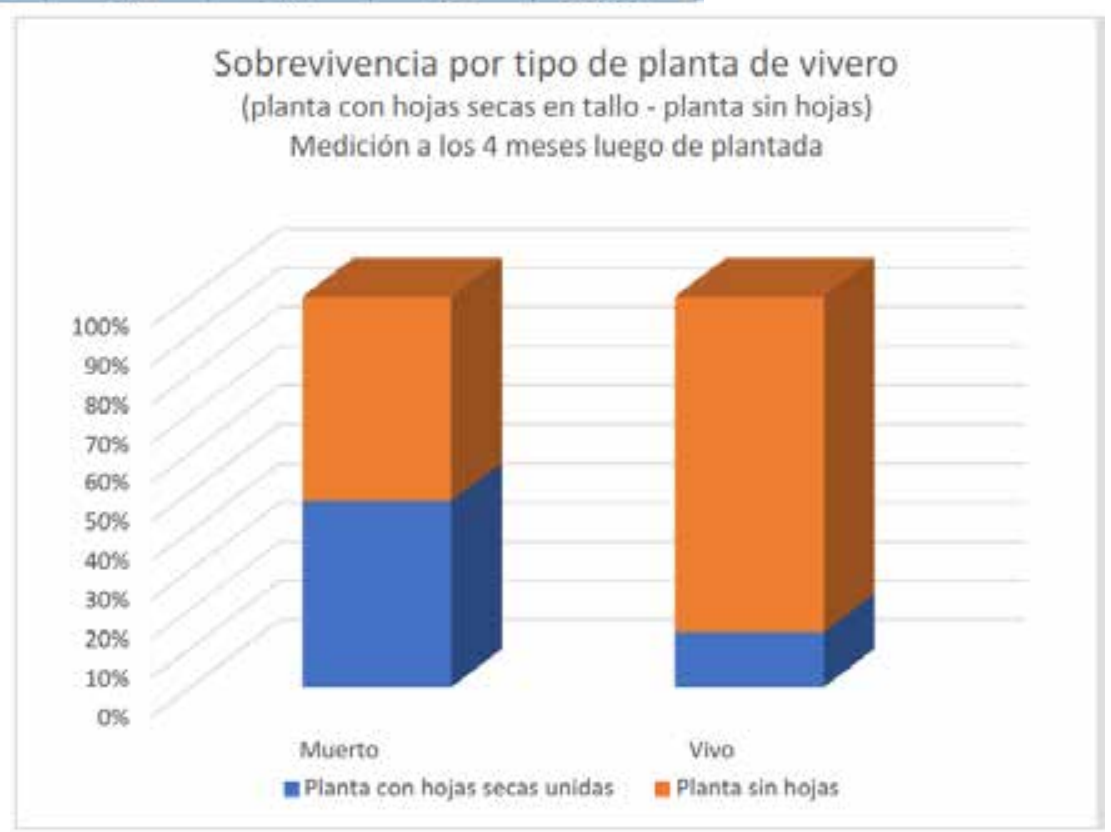

Figura 11. Sobrevivencia de las plantas en el campo, de acuerdo al tipo de planta que proviene del vivero. 
diversidad biológica, y proveer a diferentes usuarios de material vegetal de calidad, con su paquete tecnológico asociado (protocolos de propagación, producción en viveros, y manejo a campo) para posicionarnos en el nuevo paradigma de la economía circular o bioeconomía basada en la biodiversidad y la biotecnología. La producción de plantas para abastecer un mercado cada vez más demandante en cantidad y calidad, requiere, sin duda, de un sistema eficiente de propagación, que incluya el uso de técnicas tradicionales y de las biotecnologías. Asegurar que los productores, silvicultores, paisajistas y restauradores tengan un acceso oportuno a semillas y a material de propagación de buena calidad es uno de los elementos más importante de una producción y desarrollo exitosos ${ }^{1}$. El grupo de trabajo, dentro del LIMAD, apunta a convertirse en proveedor de tecnología básica para la producción de algunas especies vegetales de múltiples usos, para las cuales se está completando su caracterización y sistema de reproducción. El paquete tecnológico a desarrollar incluirá la asesoría especializada y, eventualmente, el desarrollo de nuevos productos, ya que las técnicas a instalar pueden extenderse a otras especies que demande el mercado.

\section{Referencias bibliográficas}

1. FAO 195.Material de propagación de calidad declarada ESTUDIO FAO PRODUCCIÓN Y PROTECCIÓN VEGETAL 195 Protocolos y normas para cultivos propagados vegetativamente Consulta de expertos Lima, 27-29 de noviembre de 2007 Coordinada por Juan Fajardo, NeBambi Lutaladio, Michael Larinde y Cadmo Rosell División de Producción y Protección Vegetal de la FAO y lan Barker, Willy Roca y Enrique Chujoy Centro Internacional de la Papa (CIP)

2. Bisognin, Dilson Antônio. (2011). Breeding vegetatively propagated horticultural crops. Crop Breeding and Applied Biotechnology, 11(spe), 35-43. https://doi.org/10.1590/S198470332011000500006

3. Morales, M.S., R. Villalba, H.R. Grau \& L Paolini. 2004. Rainfall controlled tree growth in high elevation subtropical treelines. Ecology, 85: 3080-3089.

4. Rada, F., C. García-Núñez, C. Boero, M. Gallardo, M. Hilal, J. González, F. Prado, M. Liberman-Cruz \& A. Azócar. 2001. Low temperature resistance in Polylepis tarapacana, a tree growing at the highest altitudes in the world. Plant, Cell \& Environment 24: 377-381.

5. Azócar, A., F. Rada \& C. García-Núñez. 2007. Functional characteristics of the arborescent genus Polylepis along a latitudinal gradient in the high Andes. Interciencia 32: 663-666.

6. Kessler, M. 1995. The genus Polylepis (Rosaceae) in Bolivia. Candollea 50: 131-171.

7. Beck, S.G., A.I. Domic, C. García, R.I. Meneses, K. Yager \& S. Halloy. 2010. Museo Nacional de Historia Natural. La Paz, Bolivia. 253 pp.

8. Cabrera, Á.L. 1971. Fitogeografía de la República Argentina. Boletín de la Sociedad Argentina de Botánica 14: 1-42.

9. Renison, D., I. Hensen, R. Suárez, A.M. Cingolani, P. Marcora \& M.A. Giorgis. 2010. Soil conservation in Polylepis mountain forests of Central Argentina: Is livestock reducing our Natural capital? Austral Ecology 35: 435-443.
10. Moore, M. 1986. Manual de ensayos al tetrazolio. Comité de tetrazolio de la asociación internacional de ensayos de semillas. Madrid. $92 \mathrm{pp}$

11. Boeri P y Sharry S. 2018. Somatic embryogenesis of alpataco (Prosopis alpataco L.). In: Forestry Sciences, Shri Mohan, Jain and Pramod Gupta (Eds). Vol 85: Step Wise Protocols for Somatic Embryogenesis of Important Woody Plants, Vol II Chapter 16: 189:198. ISSN 0924-5480. DOI 10.1007/978-3-319-79087-9 Springer International Publishing. 451pp.

12. Bertoli, B. Análisis de crecimientos iniciales de plantación de Quercus robur en Loberia, Pcia. de Buenos Aires, Argentina. Disponible en https://www.academia.edu/14744812/An\%C3\%A1lisis_de_crecimientos_iniciales_de_plantaci\%C3\%B3n_de_Quercus_robur_en_Loberia_Pcia_de_Buenos_Aires_Argentina

13. Jovanovic, M. y Tucovic, A. 1975. Genetics of common and sessile oak (Quercus robur L. and Q. petraea Liebil.) Anales forestales. 7: 23-53.

14. Kleinschmit, J. 1993. Intraspecifict variation of growtht and adaptative traits in European oak species.Ann. Sci. For. (1993) 50, Suppl. 1

15. Domic, A.I., E. Mamani \& G. Camilo. 2013. Fenología reproductiva de la kewiña (Polylepis tomentella, Rosaceae) en la puna semihúmeda de Chuquisaca (Bolivia). Ecología en Bolivia 48 (1): 31-45.

16. Murashige T. and Skoog F. 1962. A revised medium for rapid growth and bio-assays with tobacco tissue cultures. Physiol. Plant. 15, 473-497.

Received: 23 noviembre 2020

Accepted: 10 enero 2021 